\title{
Errors of Clinical Laboratory and Its Impact on Patient Safety
}

\author{
Elisabet González Lao1,2, Ángel Salas García ${ }^{3}$, Marta Buxeda Figuerola², Ester Moreno², \\ Ariadna Hernández Paraire ${ }^{2}$
}

\footnotetext{
${ }^{1}$ Departament of Biochemistry and Molecular Biology, Universidad Autònoma de Barcelona, Bellaterra (Barcelona), Spain

${ }^{2}$ Emergency Laboratory, CATLAB, Terrassa (Barcelona), Spain

${ }^{3}$ Foundation of Quality Control in Medicine Laboratories (FPCQLC), Barcelona, Spain

Email: gonzalezlaoelisabet2@gmail.com, asalasrooms@gmail.com,mbuxeda@catlab.cat
}

How to cite this paper: Lao, E.G., García, Á.S., Figuerola, M.B., Moreno, E. and Paraire, A.H. (2017) Errors of Clinical Laboratory and Its Impact on Patient Safety. Open Journal of Social Sciences, 5, 243253.

https://doi.org/10.4236/jss.2017.53022

Received: February 22, 2017

Accepted: March 26, 2017

Published: March 31, 2017

Copyright $\odot 2017$ by authors and Scientific Research Publishing Inc. This work is licensed under the Creative Commons Attribution International License (CC BY 4.0).

http://creativecommons.org/licenses/by/4.0/

\begin{abstract}
The aim of this study is to analyse the potential risks of medical laboratory activities in all processes: Strategic, operational (pre-preanalytical, preanalytical, analytical, postanalytical and post-postanalytical) and support. Also, we value the impact of these risks in the patient safety. The methodology used in this study to identify and estimate the possible failure modes was the Failure Model and Effects Analysis (FMEA). The real failures then were registered in the same processes according to the methodology Failure Reporting Analysis and Corrective Action System (FRACAS). Moreover, it used the basis of available information of the laboratory quality system. The Risk Priority Number (RPN) with FMEA and FRACAS was calculated for every laboratory processes and it was made a comparative of the results obtained with both methodologies. Based on these results, we made the risk map in medical laboratory. These results allowed us identifying critical points in all laboratory processes and prioritize the control of these points. Furthermore, it helped to select preventive or corrective action that should be incorporated in the laboratory improvement planning and risk management.
\end{abstract}

\section{Keywords}

Patient Safety, Medical Laboratory, Risks, Failure Modes, Processes

\section{Introduction}

Patient safety is defined as the absence of avoidable patient harm during the process of medical attention.

All medical attention brings inherent risk of adverse events (AE) that could cause injury, disabilities and even death of the patient. 
Based on studies conducted by Brennan [1], in 1999 Kohn published "To err is human: Building a Safer Health System" [2]. This paper told that at least $1,000,000$ of AE happen in the United States yearly, and carry on the death of 44,000 to 98,000 people. This studies a real important revolution in health world, being aware of the error rate attributable to health system that has great impact on patients. At the beginning of the 2000s some initiatives appeared and some strategies were proposed to analyze and to see how you can reduce the rate of preventable errors.

Patient safety is a target for health systems and is a fundamental principle of healthcare, as well as an important component of quality management.

The main global health organizations have incorporated patient safety in their review of work practices. Among these, the World Alliance for Patient Safety, from the 55th Health Conference in October 2004 found that the professional services of health care play an important role in risk management and in creation of safer health systems [3]. The president of that alliance, L. Donaldson, refers to the role of medical laboratory in patient safety [4].

Several studies about risk management and patient safety analyze their involvement in it scope. We highlight the Spanish National Study on Hospitalisation-Related Adverse Events (ENEAS) in 2005 [5], which was part of a quality program of the national health system and showed that $42.6 \%$ of the Adverse Events (AE) were preventable. In the laboratory, AE rate according to some reports by Plebani [6] fluctuates from $2.7 \%$ to $12 \%$.

Nowadays, quality management systems are implemented in medical laboratories. Their aims are reducing potential risks and improve patient safety [7] [8] [9].

The information provided by the medical laboratory has a direct impact on patient safety and a fault in any of processes strategic, operational (preanalytical, analytical, postanalytical) and support, could affect patients. An improvement in the safety of the various processes brings to light the potential failure modes in the laboratory and try to solve them.

To provide useful and reliable information to the clinician, it is important to emphasise the need to design risk and processes map in the laboratory [10], together with quality indicators that allow monitoring and risk management [11].

Our study aims calculate the impact of the failure modes in a medical laboratory and compare the risk with two risk management tools: Failure Mode and Effects Analysis (FMEA) versus the Failure Reporting Analysis and Corrective Action System (FRACAS). Use FMEA to estimate the potential risks and FRACAS to make real errors analysis.

\section{Methodology}

The scope of application is all processes in the medical laboratory (Catlab) at Consorcio Sanitario de Terrassa Hospital (CST). Medical laboratory was certified with ISO 9001:2000 Quality Management since 2004 and nowadays has been accredited according to UNE-EN ISO 15,189:2013. 
Consorcio Sanitario de Terrassa hospital manages 340 beds for intensive care patients and 32 beds for penitentiary patients. In its hospital network provides services to 34 primary care centres and two specialized primary care centres. It serves a population of almost 400,000 people.

Process map of medical laboratory was made with Visio Standard $2007 \mathrm{Mi}$ crosoft Office program (Figure 1), which provided a global perspective of the laboratory.

The study was made about 90 possible modes of failure detected by the Failure Model and Effects Analysis (FMEA) model applied to laboratory processes [12] [13]. FMEA is a preventive and proactive tool. It analyzes the quality, safety and/or reliability of a system performance operation, identifying possible failure modes presented, and to apply preventive actions to avoid problems that could be manifested themselves in the future.

The failure modes were identified from the literature [14] [15] [16] and a brainstorming conducted among a working group of laboratory professionals.

FMEA allowed identify potential failure modes and estimate risk through a table of three variables (Table 1): severity, frequency and detection [12] [17]. The severity score variable is based on a scale from 1 to 10 , being 1 the least severe value and 10 the worst. The variable frequency is based on a scale from 1 to 10, being 1 the least likely to appear and 10 the highest. Finally, the variable detection, it is also classified on a scale from 1 to 10 , but in this case 10 means a minor probability to detect and 1 a higher one. With the product of these three variables the risk priority number (RPN), has a potential value between 1 and

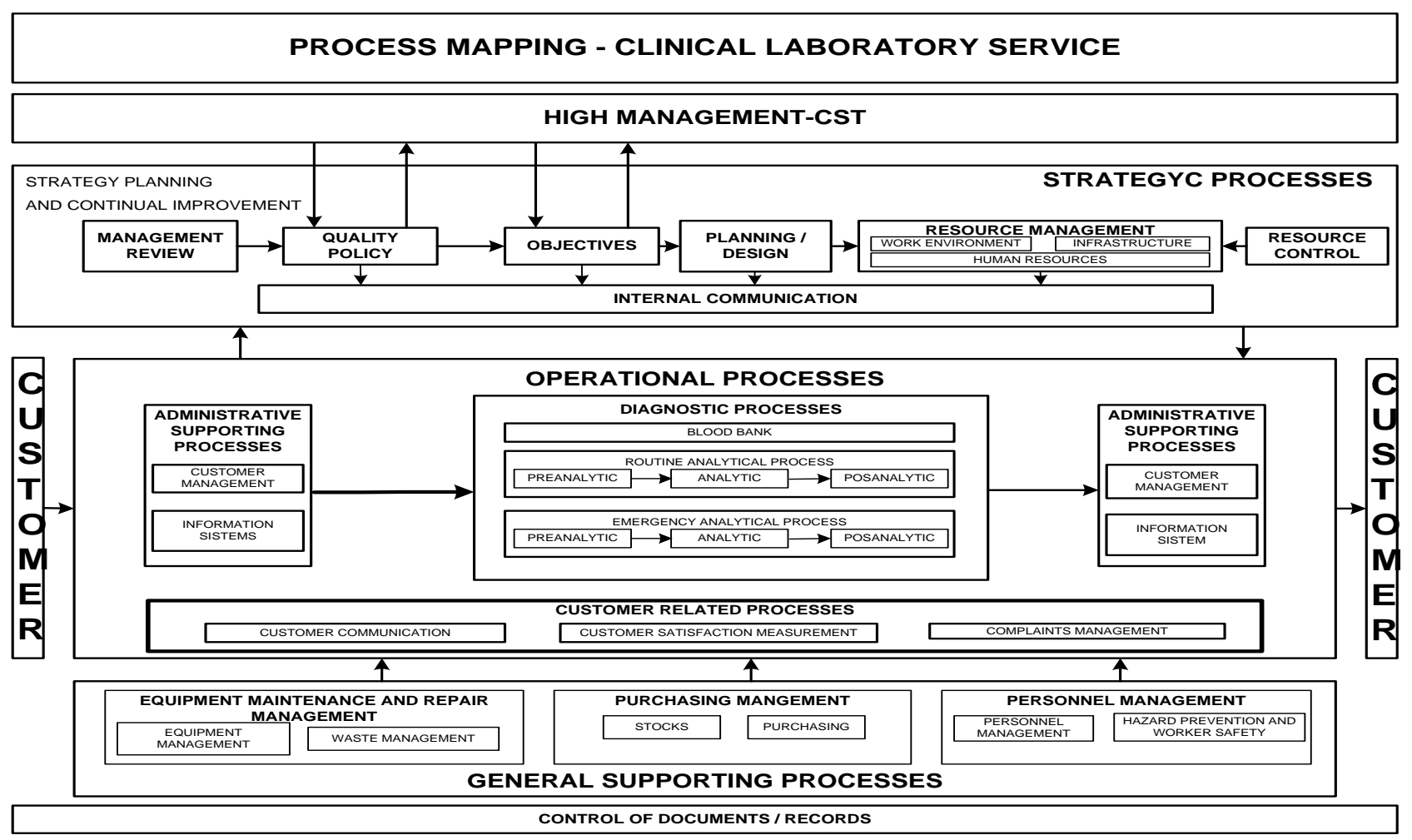

Figure 1. Processes map of medical laboratory. 
Table 1. Risk assessment values.

\begin{tabular}{cccccc}
\hline Scale & Severity & Detection & \multicolumn{2}{c}{ Frequency } & Frequency/Indicator \\
\hline 10 & Highly hazardous & Non-detectable & 1 in 2 & Very high & 0.5 \\
9 & Hazardous & Very improvable & 1 in 3 & Very high & 0.33 \\
8 & Very high & Improvable & 1 in 8 & High & 0.125 \\
7 & High & Very low & 1 in 20 & High & 0.05 \\
6 & Moderate & Low & 1 in 80 & Moderate & 0.0125 \\
5 & Low & Moderate & 1 in 400 & Moderate & 0.0025 \\
4 & Very low & Moderately high & 1 in 2000 & Low & 0.0005 \\
3 & Minor & High & 1 in 15,000 & Low & $6 \times 10^{-5}$ \\
2 & Very minor & Very high & 1 in 150,000 & Very low & $6 \times 10^{-6}$ \\
1 & None & Highly detectable & 1 in $1,500,000$ & Remote & $6 \times 10^{-7}$ \\
\hline
\end{tabular}

1000. From this way those risks were evaluated which could have direct or indirect impact on patient safety.

Then Failure Reporting Analysis and Corrective Action System (FRACAS) [15] was used. It is a corrective and reactive tool that allows analyzing variables associated with the damage and factors that explain it. FRACAS uses only two variables, severity and frequency with the same scale than FMEA for severity. For frequency, annual indicators were calculated and with the objective to harmonize with FMEA [17] the same scale was used Table 1, they were transformed to the same FMEA frequency scale used. With the product of these two variables the risk priority number (RPN), has a value between 1 and 100 .

FRACAS allowed a real calculation of the frequency of detected faults and the severity of them. It is a dynamic tool that can identify and incorporate unanticipated errors in the FMEA [18]. It was used information from the quality management system of the laboratory (audits, management reviews, indicators, nonconformities, etc.) to do this calculation.

Risk and processes maps were made with a Visio program from the results of FMEA and FRACAS [10].

This study allowed the calculation of the potential risk in the preanalytical, analytical and postanalytical processes, as well as strategic and support processes of medical laboratory.

\section{Results}

The processes map of medical laboratory shows the activities in each process and a general viewer of laboratory medicine (Figure 1 ).

The results show the priority risks identified by FMEA. These risks are classified according to the risk priority number (RPN). The five failure modes with maximum NPR for each process are presented in Table 2.

Detected failure modes are classified by FRACAS according to risk priority number (RPN). Five failures with maximum RPN are presented for each process (Table 3). 
Table 2. Classified failure modes by FMEA.

\begin{tabular}{|c|c|c|}
\hline PROCESSES & FAILURE MODES & $\begin{array}{l}\text { NUMBER OF } \\
\text { PRIORITY }\end{array}$ \\
\hline \multirow{5}{*}{ 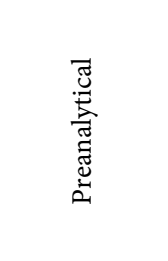 } & Incorrect temperature of sample transport & 252 \\
\hline & Clotted sample & 180 \\
\hline & Hemolysed sample & 180 \\
\hline & Difficulty of obtaining a sample. Sample obtained is not correct & 162 \\
\hline & Wrong container drawn & 126 \\
\hline \multirow{5}{*}{ 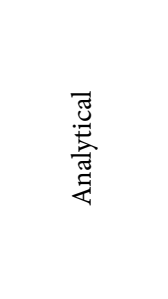 } & Inappropriate use of equipment or incorrect maintenance & 210 \\
\hline & Incorrect validation of previous analytical results & 180 \\
\hline & $\begin{array}{l}\text { Failure in relation sample-diagnostic reactive (interferences, } \\
\text { prozone effects, viscosity...) }\end{array}$ & 126 \\
\hline & Wrong magnitude selected in the request & 108 \\
\hline & Adverse environmental conditions & 108 \\
\hline \multirow{5}{*}{ 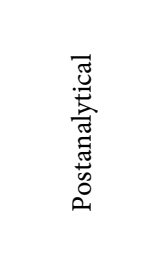 } & Misinterpreted results & 280 \\
\hline & Inadequate performance of the patient results & 280 \\
\hline & Critical value not notified & 270 \\
\hline & Alert value not recognized & 189 \\
\hline & Entry error results & 180 \\
\hline \multirow{5}{*}{ 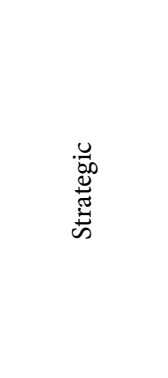 } & Management error of the corrective and improvement actions & 80 \\
\hline & $\begin{array}{l}\text { Failures in the organization of the indicators in preanalytical } \\
\text { processes }\end{array}$ & 40 \\
\hline & $\begin{array}{l}\text { Failures in the organization of the indicators in analytical } \\
\text { processes }\end{array}$ & 40 \\
\hline & $\begin{array}{l}\text { Failures in the organization of the indicators in postanalytical } \\
\text { processes }\end{array}$ & 40 \\
\hline & Lines of responsibility are poorly-defined & 14 \\
\hline \multirow{5}{*}{ 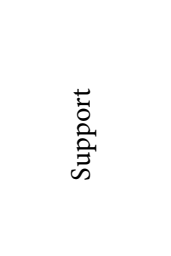 } & Error or failures of staff competence & 14 \\
\hline & Failure of replacement of staff & 12 \\
\hline & Failure of installation maintenance & 10 \\
\hline & Failure of reagent delivery (outstanding stocks) & 7 \\
\hline & Lack or inappropriate health training & 7 \\
\hline
\end{tabular}

Compare the results obtained by FMEA and FRACAS according risk priority. It presents only 10 faults with major RPN according to FMEA (Table 4).

Compare the results obtained by FRACAS and FMEA according the risk priority. It shows only the top 10 failures with higher RPN, according to FRACAS (Table 5).

Percentage (\%) distribution of failure modes identified according the affected process shows in Table 6.

The results obtained are distributed in the risk map.

The risk map allows us to have a global view on each activity of risk estimation and detection of failure modes. The results show AMFE versus FRACAS in each affected process. 
Table 3. Classified failure modes by FRACAS.

\begin{tabular}{|c|c|c|}
\hline PROCESSES & FAILURES & $\begin{array}{l}\text { NUMBER OF } \\
\text { PRIORITY }\end{array}$ \\
\hline \multirow{5}{*}{ 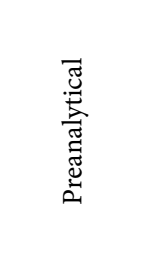 } & Not sample & 42 \\
\hline & Hemolysed sample & 42 \\
\hline & Clotted sample & 36 \\
\hline & Insufficient sample amount & 36 \\
\hline & Wrong container/incorrect sample & 30 \\
\hline \multirow{5}{*}{ 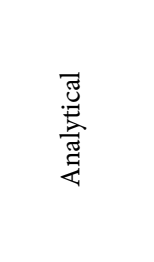 } & Incorrect interpretation of internal control results & 42 \\
\hline & Lack or inappropriate staff training & 36 \\
\hline & Problems of method or analytical mode & 32 \\
\hline & Wrong internal controls & 30 \\
\hline & Validation patient results before internal controls & 30 \\
\hline \multirow{5}{*}{ 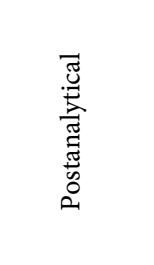 } & Results not entered in the database & 30 \\
\hline & Misinterpreted results & 28 \\
\hline & Misidentification among patients & 24 \\
\hline & Error of decimal result & 18 \\
\hline & Informed test with wrong results & 18 \\
\hline \multirow{5}{*}{ 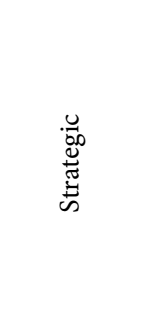 } & Wrong Management of the corrective and improvement actions & 10 \\
\hline & $\begin{array}{l}\text { Failures in the organization of the indicators in preanalytical } \\
\text { processes }\end{array}$ & 3 \\
\hline & Failures in the organization of the indicators in analytical processes & 3 \\
\hline & $\begin{array}{l}\text { Failures in the organization of the indicators in postanalytical } \\
\text { processes }\end{array}$ & 3 \\
\hline & Poorly-defined responsibility & - \\
\hline \multirow{5}{*}{ 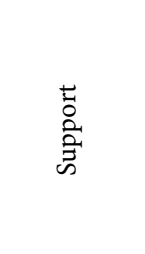 } & Failure of reagent delivery (outstanding stocks) & 7 \\
\hline & Error of staff competence & 7 \\
\hline & Lack or inappropriate health training & 7 \\
\hline & Power blackouts not notified during working hours & 7 \\
\hline & Failure of replacement of staff & 6 \\
\hline
\end{tabular}

Table 4. Comparison of the top risk numbers FMEA versus FRACAS.

\begin{tabular}{ccc}
\hline FAILURES OF MODE & AMFE & FRACAS \\
\hline Misinterpreted results & 280 & 28 \\
Calculation mistakes & 280 & 7 \\
Not notified critical/alert values & 270 & - \\
Inappropriate transport temperature & 252 & - \\
Improper use of equipment or maintenance & 210 & - \\
Warning/safety values not identified & 189 & - \\
Clotted sample & 180 & 36 \\
Hemolysed sample & 180 & 42 \\
Not correct validation of the results & 180 & - \\
Informed test with wrong results & 180 & -
\end{tabular}


Table 5. Comparison of the top risk numbers FRACAS versus FMEA.

\begin{tabular}{ccc}
\hline FAILURES & FRACAS & AMFE \\
\hline Hemolysed sample & 42 & 180 \\
Lack of sample & 42 & 126 \\
Misinterpreted internal controls & 42 & 72 \\
Clotted sample & 36 & 180 \\
Insufficient sample amount & 36 & 72 \\
Lack or inappropriate health training & 36 & 12 \\
Problems of method or analytical mode & 32 & 24 \\
Validation of the patient results without internal checking of the & 30 & 72 \\
controls & 30 & 126 \\
Wrong sample container & 30 & 54 \\
\hline Results not notified &
\end{tabular}

Table 6. Failure modes identified (\%) by processes according to FMEA and detected faults (\%) according to FRACAS.

\begin{tabular}{cccc}
\hline & PROCESSES & AMFE (\%) & FRACAS (\%) \\
\hline \multirow{3}{*}{ Operational } & Preanalytical & 34.2 & 48.4 \\
& Analytical & 26.5 & 28.2 \\
& Postanalytical & 35.1 & 17.2 \\
& Strategic & 2.9 & 2.0 \\
& Support & 1.3 & 4.2 \\
\hline
\end{tabular}

\section{Discussion}

Any failure in the processes established into the laboratory can lead to consequences in patients, being a key component in relation to patient safety [19] [20]. That is why we have to manage these failures and implement improvement plans to reduce them [7]. Nowadays, it is seen a tendency to move from the culture of error detection to the management of risk in all quality systems of clinical laboratories [21].

In the literature, authors believe that the study of the impact of risks must be made in operational, strategic and support processes. There are studies showing these processes by designing indicators, such as related to the competence of professionals, customer service [22] or indicators associated with strategic support processes [23] [24] or operational and support processes [11]. It must be stressed, however, that most publications are focused on the operational processes (preanalytical, analytical and postanaytical) [25] [26] [27] [28] or preanalytical and postanalytical [29] [30] or exclusively preanalytical [31] [32].

This series of quality indicators described in those studies, as well as patient risk, come to meet the need to comply with the strategic lines that are being defined in the health sector, related to the dissemination of the culture of patient safety and the implementation of improvement plans to increase safe practices in this environment. 
On the other hand, the two standards of broad application in laboratories (UNE-EN ISO 9001:2015 and UNE-EN ISO 15,189: 2013) are also involved in the risk management of the patient [8] [9], although the design of its indicators is not made from the use of tools such as FMEA and FRACAS. Therefore, we found it interesting to carry out this study in all laboratory processes using both FMEA and FRACAS tools because they are widely used in the clinical laboratories to highlight the need for implement risk management.

The application of these tools is not as widespread as indicators of quality of clinical laboratories. However, it is interesting the Astion and colleagues' study [33] that analyzed the impact on the patient of incidents in the laboratory and compares real potential adverse events. Another interesting study was done by A. Giménez and colleagues [34] which used FMEA only in preanalytical processes.

In our study, results from FMEA were obtained with three variables and FRACAS with two variables. Detectability in FRACAS is real because the errors are registered, while FMEA estimates detectability. This fact is reflected in the results presented in Tables 2-5.

Table 6 shows the percentage of distribution of failures in laboratory processes using the FMEA tool and the percentage of distribution of errors using the FRACAS tool. It is noticeable that there is a significant difference in the support processes between FRACAS and FMEA (4.2\% FRACAS compared with 1.3\% FMEA).

Discrepancies are observed between preanalytical (48.4\% FRACAS versus 34.2 FMEA) and postanalytical (17.2\% FRACAS versus 35.1\% FMEA) processes. However, the results showed a good agreement in analytical processes $(28.2 \%$ FRACAS versus $26.5 \%$ FMEA).

If we compare our results with those obtained by Plebani [35], we have similar results for the preanalytical processes (in FRACAS $48.4 \%$ versus $46 \%-68.2 \%$ of Plebani) and the postanalytical processes (35.1\% compared FMEA 18.5\% - 47\% of a Plebani). However, in analytical processes the results do not match the two studies (26.5\% FMEA and FRACAS 28.2\%, versus 13\% and 7\% Plebani).

Strategic and support processes contribute to patient risk rate much lower than the operative processes. As regards strategic by low estimated frequency and in support processes due to low gravity failure modes.

The processes map adds information about the organization of processes and subprocesses in clinical laboratory. Together with the risk map, it gives us a global view of the distribution of failures in each of the processes.

It has been made the calculation of RPN, to assess the impact of potential risks. From these results, it could be developed an improvement plan to implement corrective and preventive actions, in accordance with the standards ISO 15,189:2013 [8] and ISO 9001:2015 [9]. Keep in mind that prioritization must be made from the calculation of the failure modes and not from the subprocesses or processes because potentially serious risks (but less frequent) could be masked.

\section{Conclusions}

The fact of identifying potential failure modes by FMEA tool makes to review 


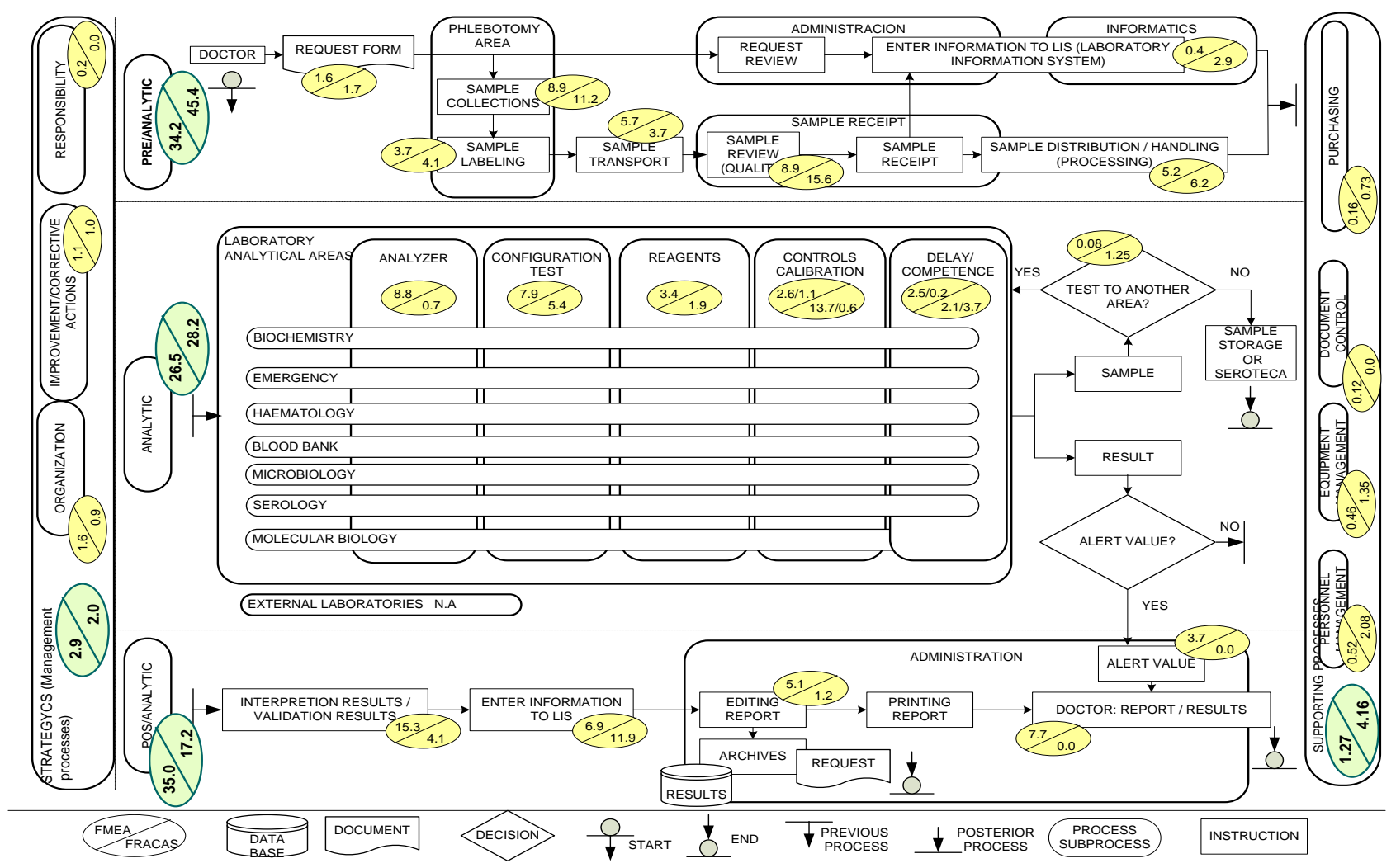

Figure 2. Risks map of medical laboratory.

meticulously the processes implemented to detect all possible faults in the various activities and stages involved in them. It was decided to make the study of risks in all laboratory processes (operational, strategic and support), since activities performed in all processes can cause potential risks and can have an impact on patient safety as shown in Figure 2.

FMEA allows detecting critical points in terms of the patient risk and FRACAS highlights the priorities to control these points and help to select preventive or corrective actions that we should be incorporated in the laboratory improvement planning.

If FMEA is compared versus FRACAS, the difference is that indices of risk priority are higher in FMEA in postanalytical processes, while comparing FRACAS versus FMEA the rates of risk priority are higher in preanalytical processes.

The greatest impact of potential real errors in patients appear in activities related to operational processes, which are more related to the actions of health professionals on patients.

It is important to note that FMEA is a subjective tool and that to be able to make a real study of failures FRACAS has to be performed.

On the basis of the results obtained of FMEA and FRACAS a strategic risk management plan should be implemented.

It is conclusive the need for risk management in clinical laboratories and monitoring them within the quality plan, a fact that would lead to an increase on patient safety. 


\section{References}

[1] Brennan, T.A., Leape, L.L., Laird, N.M., et al. (1991) Incidence of Adverse Events and Negligence in Hospitalized Patients Results of the Harvard Medical Practice Study I. The New England Journal of Medicine, 324, 370-376. https://doi.org/10.1056/NEJM199102073240604

[2] Kohn, L.T., Corrigan, J.M. and Donaldson, M.S. (1999) To Err Is Human. Building a Safer Heath System. National Academy Press, Washington DC.

[3] World Health Organization (2002) The World Health Report 2002. Reducing Risks, Promoting Healthy Life. WHO, Geneva. http://www.who.int/whr/2002/en/

[4] Donaldson, L. (2007) Laboratory Medicine and Patient Safety. Foreword. Clinical Chemistry and Laboratory Medicine, 45, 697-699.

[5] Aranaz Andrés, J.M., Aibar Ramón, C., Vitaller Burillo, J., et al. (2006) Spanish National Study on Hospitalisation-Related Adverse Events (ENEAS).

[6] Plebani, M. (2010) The Detection and Prevention of Errors in Laboratory Medicine. Annals of Clinical Biochemistry, 47, 101-110.

https://doi.org/10.1258/acb.2009.009222

[7] International Organization of Standardization (2010) Medical Laboratories-Reduction of Error through Risk Management and Continual Improvement. CEN ISO/TS 22367, Geneva.

[8] International Organization of Standardization (2012) Medical Laboratories. Requirements for Quality and Competence. ISO 15189, Geneva.

[9] International Organization of Standardization (2015) Quality Management Systems. Requirements. ISO 9001, Geneva.

[10] García Gómez, M.M. (1994) Risk Maps. Concept and Methodology for Its Elaboration. Revista de Sanidad e Higiene Pública, 68, 443-453.

[11] Plebani, M., Astion, M., Barth, J., et al. (2014) Harmonization of Quality Indicators in Laboratory Medicine. A Preliminary Consensus. Clinical Chemistry and Laboratory Medicine, 52, 951-958. https://doi.org/10.1515/cclm-2014-0142

[12] Cuatrecasas, L. (2005) Comprehensive Quality Management. 3rd Edition, Gestion 2000, Barcelona.

[13] Kenneth Crow DRM Associates. http://www.npd-solutions.com/fmea.html

[14] Clinical and Laboratory Standards Institute (2007) Management of Nonconforming Laboratory Events; Approved Guideline. GP32-A. CLSI, Wayne.

[15] Clinical and Laboratory Standards Institute (2009) Risk Management Techniques to Identify and Control Laboratory Error Sources; Approved Guideline-Second Edition. EP18-A2. CLSI, Wayne.

[16] Clinical and Laboratory Standards Institute (2011) Laboratory Quality Control on Risk Management; Approved Guideline. EP23-A. CLSI, Wayne.

[17] Govindarajan, R. (2009) Health Disorder Has a Cure. ICG Marge Médica Books, Barcelona.

[18] Krouwer, J. (2006) Dynamic Rather than Static Performance Measures Are Needed to Improve Patient Safety. Accreditation and Quality Assurance, 11, 644-646. https://doi.org/10.1007/s00769-006-0199-4

[19] Stankovic, A. (2004) The Laboratory Is a Key Partner in Assuring Patient Safety. Clinics in Laboratory Medicine, 24, 1023-1035.

[20] Wagar, E. and Tuan, S. (2007) The Laboratory and Patient Safety. Clinics in Laboratory Medicine, 27, 909-930. 
[21] Plebani, M. (2007) Errors in Laboratory Medicine and Patient Safety: The Road Ahead. Clinical Chemistry and Laboratory Medicine, 45, 700-707. https://doi.org/10.1515/CCLM.2007.170

[22] Plebani, M., Ceriotti, F., Messeri, G., et al. (2006) Laboratory Network of Excellence: Enhancing Patient Safety and Service Effectiveness. Clinical Chemistry and Laboratory Medicine, 44, 150-160. https://doi.org/10.1515/CCLM.2006.028

[23] Ricos, C., Biosca, C., Ibarz, M., et al. (2008) Quality Indicators and Specifications for Strategic and Support Processes in Laboratory Medicine. Clinical Chemistry and Laboratory Medicine, 46, 1189-1194. https://doi.org/10.1515/CCLM.2008.225

[24] Ruiz, R., Llopis, M., Biosca, C., et al. (2010) Indicators and Quality Specifications for Strategic and Support Processes Related to the Clinical Laboratory. Four Years' Experience. Clinical Chemistry and Laboratory Medicine, 48, 1015-1019. https://doi.org/10.1515/CCLM.2010.229

[25] Carraro, P. and Plebani, M. (2007) Errors in a Stat Laboratory: Types and Frequencies 10 Years Later. Clinical Chemistry, 53, 1338-1342. https://doi.org/10.1373/clinchem.2007.088344

[26] Alsina, M., Alvarez, V., Biosca, C., et al. (2007) Quality Indicators and Specifications for Key Processes in Clinical Laboratories; A Preliminary Experience. Clinical Chemistry and Laboratory Medicine, 45, 672-677.

[27] Szecsi, P. and Odum, L. (2009) Error Tracking in a Clinical Biochemistry Laboratory. Clinical Chemistry and Laboratory Medicine, 47, 1253-1257. https://doi.org/10.1515/CCLM.2009.272

[28] Angüiano-Sánchez, N., Perales-Quintana, M., Díaz-Olachea, C., et al. (2011) Errors in Clinical Laboratory: Evaluation of Types and Frequencies. Medicina Universitaria, 13, 133-138. (In Spanish)

[29] Laposata, M. and Dighe, A. (2007) Pre-Pre and Post-Post Analytical Error: HighIncidence Patient Safety Hazards Involving the Clinical Laboratory. Clinical Chemistry and Laboratory Medicine, 45, 712-719. https://doi.org/10.1515/CCLM.2007.173

[30] Hawkins, R. (2012) Managing the Pre- and Post-Analytical Phases of the Total Testing Process. Annals of Laboratory Medicine, 32, 5-16. https://doi.org/10.3343/alm.2012.32.1.5

[31] Lippi, G. and Guidi, G. (2007) Risk Management in Pre-Analytical Phase of Laboratory Testing. Clinical Chemistry and Laboratory Medicine, 45, 720-727. https://doi.org/10.1515/CCLM.2007.167

[32] Plebani, M. (2012) Quality Indicators to Detect Pre-Analytical Errors in Laboratory Testing. The Clinical Biochemist Reviews, 33, 85-88.

[33] Astion, M., Shojania, K., Hamill, T., et al. (2003) Classifying Laboratory Incident Reports to Identify Problems That Jeopardize Patient Safety. American Journal of Clinical Pathology, 120, 18-26. https://doi.org/10.1309/8U5D0MA6MFH2FG19

[34] Giménez, A., Molina, P., Ruiz, J., et al. (2010) Application of Failure Mode and Effects Analysis of the Pre-Analytical Phase in a Clinical Laboratory. Revista del Laboratorio Clínico, 3, 161-170. (In Spanish)

[35] Plebani, M. (2006) Errors in Clinical Laboratories or Errors in Laboratory Medicine? Clinical Chemistry and Laboratory Medicine, 44, 750-759.

https://doi.org/10.1515/CCLM.2006.123 
Submit or recommend next manuscript to SCIRP and we will provide best service for you:

Accepting pre-submission inquiries through Email, Facebook, LinkedIn, Twitter, etc. A wide selection of journals (inclusive of 9 subjects, more than 200 journals)

Providing 24-hour high-quality service

User-friendly online submission system

Fair and swift peer-review system

Efficient typesetting and proofreading procedure

Display of the result of downloads and visits, as well as the number of cited articles Maximum dissemination of your research work

Submit your manuscript at: http://papersubmission.scirp.org/

Or contact jss@scirp.org 